\title{
Thermally stable PdIn ohmic contacts to $n$-GaAs via exchange mechanism
}

\author{
D. Y. Chen and Y. A. Chang \\ Department of Materials Science and Engineering, University of Wisconsin, 1509 University Avenue, \\ Madison, Wisconsin 53706
}

\section{Swenson}

Department of Metallurgical and Materials Engineering, Michigan Technological University, 1400 Townsend Drive, Houghton, Michigan 49931

(Received 25 July 1996; accepted for publication 30 September 1996)

\begin{abstract}
Thermally stable, low-resistance ohmic contacts to GaAs (Si-doped, $n=1.6-1.8 \times 10^{18} \mathrm{~cm}^{-3}$ ) were formed using PdIn metallization sputter-deposited from an alloy target. Average specific contact resistances $\left(\rho_{c}\right)$ in the $10^{-6} \Omega \mathrm{cm}^{2}$ range were reached upon annealing at $600{ }^{\circ} \mathrm{C}$ or higher. Contacts annealed under the optimum condition of $850^{\circ} \mathrm{C}$ for $15 \mathrm{~s}$ exhibited an average $\rho_{c}$ of $2.5 \times 10^{-6}$ $\Omega \mathrm{cm}^{2}$. The $100 \mathrm{~h}$ of thermal aging at 400 or $500{ }^{\circ} \mathrm{C}$ increased their average $\rho_{c}$ to $3.0 \times 10^{-6}$ and $1.0 \times 10^{-5} \Omega \mathrm{cm}^{2}$, respectively. The ohmic behavior of the annealed contacts was ascribed to the exchange of In and $\mathrm{Ga}$ atoms between the metallization and the semiconductor and the concomitant formation of $\operatorname{In}_{x} \mathrm{Ga}_{1-x} \mathrm{As}$, whose presence at the contact interface was confirmed using cross-sectional transmission electron microscopy. (C) 1997 American Institute of Physics. [S0021-8979(97)04801-9]
\end{abstract}

\section{INTRODUCTION}

Contacts comprising Pd and In are among the most studied nonalloyed metallizations to $n$-GaAs to date. ${ }^{1-8}$ They exhibit very good electrical properties, generally yielding specific contact resistances $\rho_{c}$ in the low to mid- $10^{-6} \Omega \mathrm{cm}^{2}$ range, and show excellent uniformity and thermal stability. It is well established that the ohmic behavior of these contacts may be attributed to the formation of $\mathrm{In}_{x} \mathrm{Ga}_{1-x}$ As at the interface, which reduces the interfacial Schottky barrier height and thus facilitates electron transport between the metal and semiconductor. However, the exact chemical mechanism of $\operatorname{In}_{x} \mathrm{Ga}_{1-x}$ As formation in annealed Pd-In contacts is less well characterized. Early investigators, such as Allen et al., ${ }^{1}$ Stremsdoerfer et al., ${ }^{2}$ and Prasad and co-workers, ${ }^{4}$ concentrated on measuring electrical properties of annealed contacts and neither of them identified clearly the reaction products that ensued from thermal processing. Moreover, significant differences in metallization composition, deposition method, and annealing procedure employed by each of these investigators would have made a direct comparison of their studies difficult in any case.

Wang et $a l^{3,5}$ were the first to identify a possible mechanism for the formation of $\operatorname{In}_{x} \mathrm{Ga}_{1-x}$ As from the chemical interaction between $\mathrm{Pd}-\mathrm{In}$ metallizations and $n$-GaAs. This mechanism is termed the solid-phase regrowth mechanism, and has been described in detail by Sands, Marshall, and Wang. ${ }^{9}$ Wang et al. postulated the regrowth mechanism to proceed as follows. Pd and In are deposited in layers, with the configuration of $\mathrm{Pd} / \mathrm{In} / \mathrm{Pd} / n$-GaAs. The ratio of $\mathrm{Pd}$ to $\mathrm{In}$ is chosen to correspond to that of slightly In-rich PdIn, an intermetallic phase with the $\mathrm{CsCl}(B 2)$ structure. The contacts are formed by a two-step annealing process. Upon annealing at low temperature $\left(\sim 100{ }^{\circ} \mathrm{C}\right)$, the bottom Pd layer reacts with the GaAs substrate to form a metastable ternary compound $\mathrm{Pd}_{4} \mathrm{GaAs}$. This reaction has been well characterized in the study of $\mathrm{Pd} / \mathrm{GaAs}$ couples. ${ }^{10}$ Simultaneously, the $\mathrm{PdIn}_{3}$ phase is produced from the reaction between In layer and the outer Pd layer, resulting in the configuration of $\mathrm{PdIn}_{3} / \mathrm{Pd}_{4} \mathrm{GaAs} / n$-GaAs. During the second stage of annealing $\left(\geqslant 550{ }^{\circ} \mathrm{C}\right), \mathrm{PdIn}_{3}$ and $\mathrm{Pd}_{4} \mathrm{GaAs}$ react with each other to form PdIn and regrown GaAs. During the regrowth process some In is incorporated into the GaAs layer, forming $\mathrm{In}_{x} \mathrm{Ga}_{1-x} \mathrm{As}$, and the displaced $\mathrm{Ga}$ is incorporated into the metal layer.

Although this reaction mechanism is quite plausible, the specific means by which In is incorporated into the regrown GaAs layer is not clear. Indeed, transmission electron microscopy (TEM) by Wang et al. ${ }^{5}$ suggests that solid-phase regrowth occurs at low temperatures (e.g., $325^{\circ} \mathrm{C}$ ), yet no In is incorporated into the regrown GaAs layer. This implies that the formation of $\mathrm{In}_{x} \mathrm{Ga}_{1-x}$ As may not result from the regrowth process.

Recent work by Fu and Huang ${ }^{7,8}$ further indicates that solid-phase regrowth is not required for the formation of $\mathrm{In}_{x} \mathrm{Ga}_{1-x}$ As in Pd-In contacts to $n$-GaAs. Fu and Huang compared the electrical properties of codeposited PdIn (B2 structure) and layered $\mathrm{Pd} / \mathrm{In} / \mathrm{Pd}$ contacts to $n$-GaAs. They have found that for each initial configuration, the same $\rho_{c}-T$ relationship and the same final phase configuration $\left(\mathrm{PdIn} / \mathrm{In}_{x} \mathrm{Ga}_{1-x} \mathrm{As} / n\right.$-GaAs) are obtained upon heat treatment. Because codeposited PdIn cannot participate in the solid-phase regrowth process, a different mechanism must be responsible for the formation of $\operatorname{In}_{x} \mathrm{Ga}_{1-x}$ As at the contact interface.

The work from Fu and Huang suggests that codeposited PdIn contacts to $n$-GaAs become ohmic due to the exchange mechanism, which was postulated by Sands et al. ${ }^{11}$ and described theoretically by $\mathrm{Jan}^{12}$ and Chang, Jan, and Chen. ${ }^{13,14}$ Because PdIn and Pd/In/Pd contacts share the same $\rho_{c}-T$ relationship and final phase configuration, it is very likely that for $\mathrm{Pd} / \mathrm{In} / \mathrm{Pd}$ contacts, instead of the regrowth mechanism, it is the exchange mechanism between PdIn, which forms as a result of the regrowth process, and GaAs that gives rise to the formation of $\operatorname{In}_{x} \mathrm{Ga}_{1-x}$ As. The operation of 
the exchange mechanism has recently been demonstrated by the present investigators ${ }^{15}$ in the study of $\mathrm{PtIn}_{2}$ ohmic contacts to $n$-GaAs. (In Ref. 15 a typographical error was made concerning the doping concentration of $n$-GaAs used. It should be $1.6-1.8 \times 10^{18} \mathrm{~cm}^{-3}$ instead of $1.6-1.8 \times 10^{19}$ $\mathrm{cm}^{-3}$. In fact, the doping concentration is the same as the one used in the present study.) In this article we report the formation of ohmic contacts via the exchange mechanism between alloy target deposited PdIn and $n$-GaAs.

Our thermodynamic/kinetic study of the Ga-In-Pd-As system ${ }^{16}$ reveals that the intermetallic compound PdIn satisfies the criteria for participating in an exchange reaction with GaAs. Two solid solution phases, $\mathrm{Pd}(\mathrm{In}, \mathrm{Ga})$ (B2 structure) and $(\mathrm{In}, \mathrm{Ga}) \mathrm{As}$, are in thermodynamic equilibrium. However, the equilibrium does not exist between PdIn and GaAs, which are the specific compositions of the $\mathrm{Pd}(\mathrm{In}, \mathrm{Ga})$ and (In, Ga)As phases, respectively. There would thus be an exchange of In and $\mathrm{Ga}$ atoms upon heat treatment in order for the phases to reach their equilibrium compositions at the interface. This exchange causes a composition shift of the original phases at the interface but does not lead to the formation of any new phases. The result is the formation of $\mathrm{In}_{x} \mathrm{Ga}_{1-x}$ As at the interface, which gives rise to the contact's ohmic behavior. Accordingly, the reacted metal layer becomes $\operatorname{PdIn}_{y} \mathrm{Ga}_{1-y}$. The merit of this contact scheme is the simplicity and uniformity of the microstructure one may anticipate when no new phase forms at the contact interface. In this article the electrical behavior, as well as preliminary TEM characterization, is presented for $\mathrm{PdIn} / n-\mathrm{GaAs}$ contacts. A detailed thermodynamic/kinetic analysis of PdIn $/ n$ $\mathrm{GaAs}$ and interfacial reaction characterization will be published at a later date.

\section{EXPERIMENT}

The fabrication of contacts involves target fabrication, lithographic patterning, thin-film deposition, and thermal treatment. Contacts to be used for cross-sectional TEM characterization were prepared the same way as described below, except that the lithography was omitted. A PdIn compound target was fabricated by vacuum hot pressing a powdered PdIn master alloy. For lithographic patterning, Si-doped $\left(n=1.6-1.8 \times 10^{18} \mathrm{~cm}^{-3}\right)(100)$-oriented GaAs wafers were degreased in the sequence of trichloroethylene, acetone, and methanol under heat and ultrasonication for 5 min each. They were then rinsed in flowing de-ionized (DI) $\mathrm{H}_{2} \mathrm{O}$ and etched in HF:DI- $\mathrm{H}_{2} \mathrm{O}$ (1:10) solution for 2 min each, followed by another DI- $\mathrm{H}_{2} \mathrm{O}$ rinsing for $3 \mathrm{~min}$. Subsequently, the standard lift-off photolithographic technique defined the test pattern of an array of $65-\mu \mathrm{m}$-diam dots spaced $1500 \mu \mathrm{m}$ apart. After lithography, the substrates were again etched in a HF:DI- $\mathrm{H}_{2} \mathrm{O}(1: 10)$ solution for $2 \mathrm{~min}$, and rinsed in flowing DI- $\mathrm{H}_{2} \mathrm{O}$ for $3 \mathrm{~min}$. They were blown dry with high-purity $\mathrm{N}_{2}$, and were immediately loaded into a cryopumped vacuum chamber with the base pressure lower than $3 \times 10^{-7}$ Torr.

Thin-film deposition was accomplished by dc magnetron sputtering from a disk-shaped PdIn compound target. Metal films were deposited at a rate of $15 \mathrm{~nm} / \mathrm{min}$, under $4.0 \mathrm{mTorr}$ of high-purity Ar gas pressure. A thick film $(2.0 \mu \mathrm{m})$ was

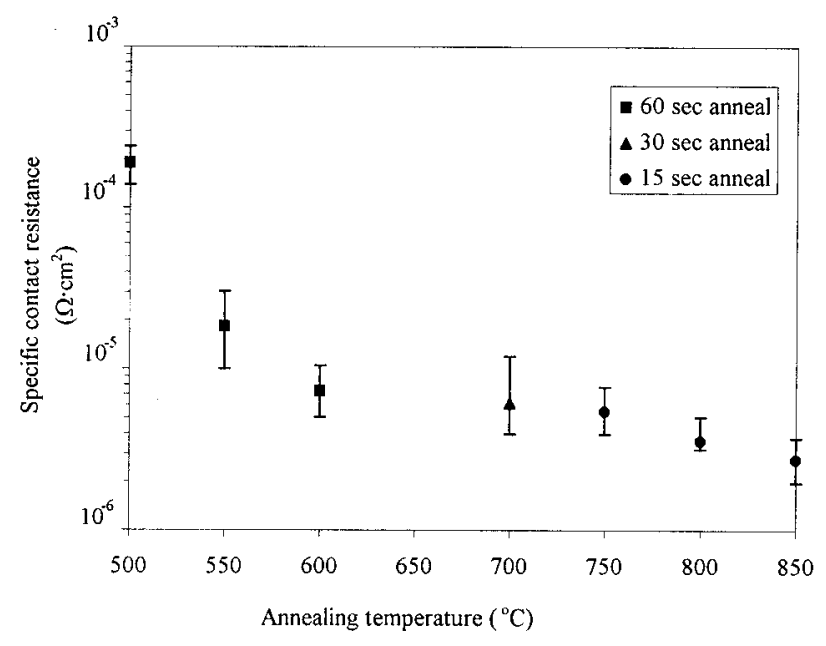

FIG. 1. Specific contact resistances of $\mathrm{PdIn} / n-\mathrm{GaAs}$ contacts as a function of annealing temperature. The symbols denote average values of at least five independent measurements. The error bars indicate the highest and lowest specific contact resistances measured for each annealing condition.

sputtered on a glass slide and analyzed by a Cameca electron microprobe to verify the composition of the sputtered film. $\mathrm{X}$-ray-diffraction analysis of this thick film, using a Nicolet diffractometer with $\mathrm{Cu} K \alpha$ radiation, confirmed that the film was single phase PdIn. All films deposited on GaAs were nominally $200 \mathrm{~nm}$ in thickness.

After sputter deposition the wafers were soaked in ultrasonically agitated acetone to remove the photoresist. The thermal treatment of the thin film contacts was then performed using an AG Associate Heatpulse Minipulse rapid thermal annealing furnace, which was ramped to the desired temperature at the rate of $50{ }^{\circ} \mathrm{C} / \mathrm{s}$. Sacrificial pieces of GaAs were laid face to face with the samples during annealing to reduce As outgassing. The furnace environment was the flowing high-purity Ar gas.

Specific contact resistances $\rho_{c}$ were measured using a modified four-point-probe method outlined by Kuphal. ${ }^{17} \mathrm{~A}$ Keithley model 236 measurement unit was employed as a current source and voltage meter. At least five independent measurements of $\rho_{c}$ were taken for each annealing condition.

After the initial heat treatment and electrical characterization, the thermal stability of the contacts was tested by long term annealing experiments. This was done by encapsulating the samples in quartz ampoules that were evacuated in a turbopumped vacuum system to pressures in the high $10^{-7}$ Torr range, and then furnace annealing at 400 or $500{ }^{\circ} \mathrm{C}$ for $100 \mathrm{~h}$.

\section{RESULTS AND DISCUSSION}

The $\rho_{c}$ of the contacts as a function of annealing temperature are given in Fig. 1. Contacts were rectifying in the as-deposited state; they became ohmic after being annealed at $500{ }^{\circ} \mathrm{C}$ for $1 \mathrm{~min}$. The $\rho_{c}$ dropped to the $10^{-6} \Omega \mathrm{cm}^{2}$ range after the contacts were annealed at $600{ }^{\circ} \mathrm{C}$ or higher. The lowest $\rho_{\mathrm{c}}\left(2.5 \times 10^{-6} \Omega \mathrm{cm}^{2}\right)$ were obtained after annealing at $850{ }^{\circ} \mathrm{C}$ for $15 \mathrm{~s}$. 

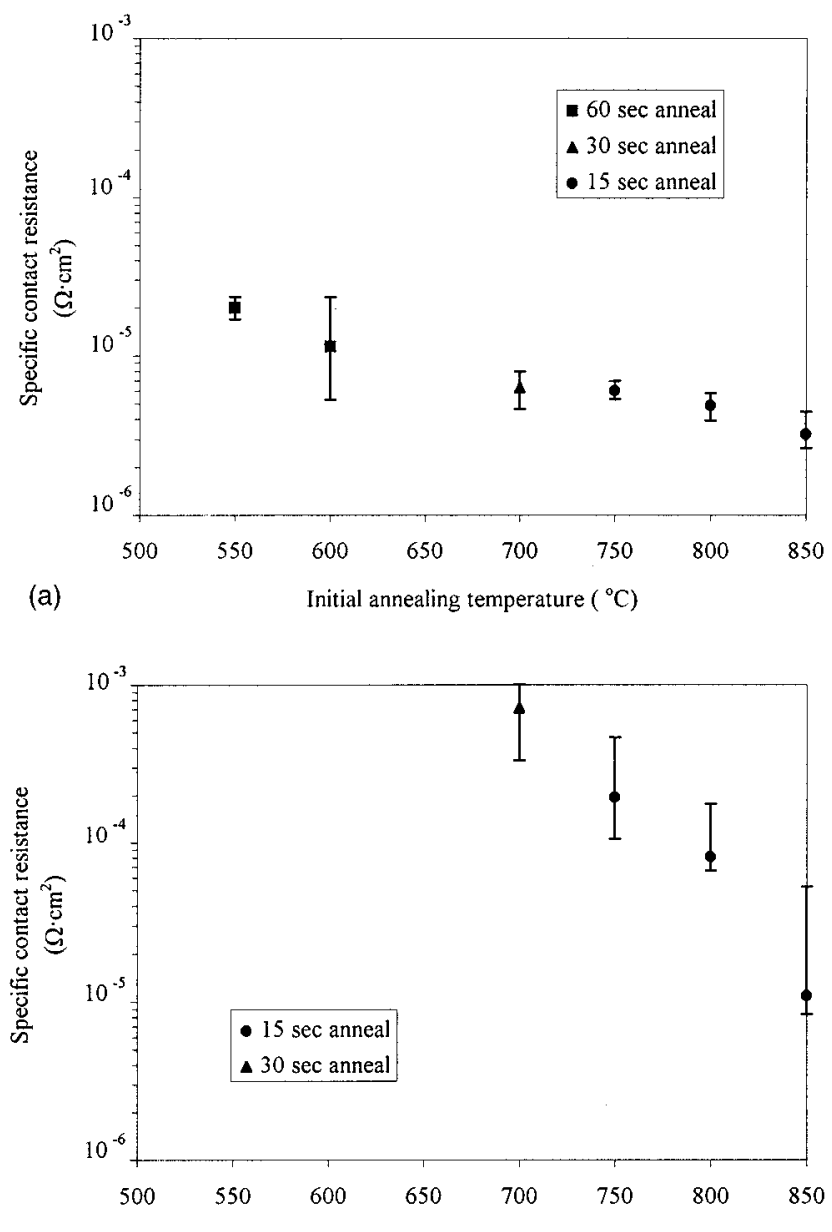

(b)

FIG. 2. Specific contact resistances of PdIn $/ n$-GaAs contacts aged for $100 \mathrm{~h}$ at (a) $400{ }^{\circ} \mathrm{C}$ or (b) $500{ }^{\circ} \mathrm{C}$ as a function of initial annealing temperature. As was the case in Fig. 1, the symbols denote average values, and the error bar indicates the highest and lowest specific contact resistances measured for each annealing condition.

The $\rho_{c}$ of the contacts after thermal aging for $100 \mathrm{~h}$ at 400 and $500{ }^{\circ} \mathrm{C}$ as a function of the initial annealing temperature are given in Figs. 2(a) and 2(b), respectively. As shown in Fig. 2(a), there was practically no degradation for the contacts thermally aged at $400{ }^{\circ} \mathrm{C}$ for $100 \mathrm{~h}$; the values of $\rho_{c}$ remain approximately the same compared with those shown in Fig. 1; however, this is not the case for contacts aged at $500{ }^{\circ} \mathrm{C}$ for $100 \mathrm{~h}$. As shown in Fig. 2(b), the $\rho_{c}$ for contacts annealed at $700,750,800$, and $850{ }^{\circ} \mathrm{C}$ are higher than the corresponding values shown in Fig. 1. The contacts annealed at $600{ }^{\circ} \mathrm{C}$ or lower became rectifying and thus had no data point in Fig. 2(b). The average $\rho_{c}$ of the contacts initially annealed at the optimum condition of $850^{\circ} \mathrm{C} / 15 \mathrm{~s}$ increased from $2.5 \times 10^{-6} \Omega \mathrm{cm}^{2}$ to $3.0 \times 10^{-6}$ and $1.0 \times 10^{-5}$ $\Omega \mathrm{cm}^{2}$ after $100 \mathrm{~h}$ treatment at 400 and $500{ }^{\circ} \mathrm{C}$, respectively. This level of thermal stability is more than sufficient to withstand the thermal processing steps for device fabrication after contact formation.

The contact interface was characterized by crosssectional TEM using a JOEL 200CX transmission electron microscope equipped with an energy-dispersive spectrometer

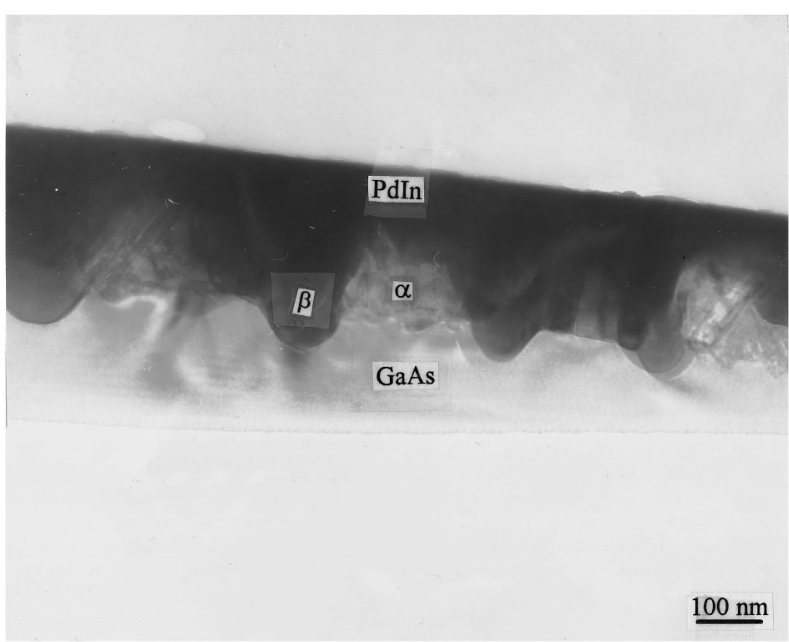

FIG. 3. Bright-field transmission electron micrograph of a cross-sectional view of $\mathrm{PdIn} / n$-GaAs contact after annealing at $600^{\circ} \mathrm{C}$ for $1 \mathrm{~min}$.

(EDS). Figure 3 is a cross-sectional TEM micrograph of a contact annealed at $600{ }^{\circ} \mathrm{C}$ for $1 \mathrm{~min}$. The interface shows an aggregate structure. The light reacted region, denoted " $\alpha$ " in Fig. 3, has a contrast similar to that of the GaAs substrate. The EDS spectrum shown in Fig. 4(a) indicates that it contains In, Ga, and As, but no Pd; it suggests that this is the reacted $\operatorname{In}_{x} \mathrm{Ga}_{1-x}$ As, which lowers the specific contact resistances. Conversely, the dark reacted region, denoted ' $\beta$ ' in Fig. 3, has a contrast similar to that of the PdIn metal. This

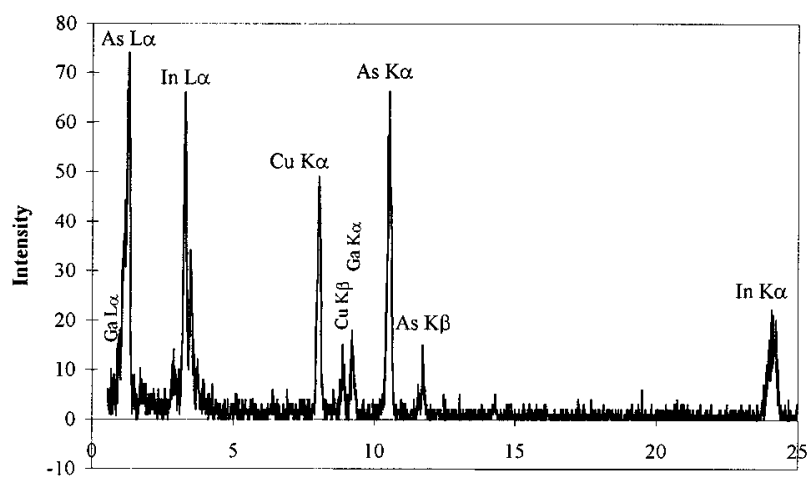

(a)

Energy (keV)

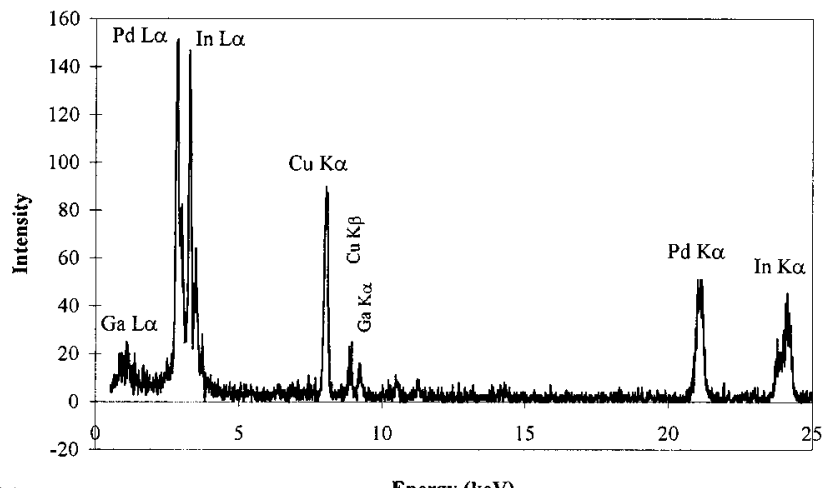

(b)

Energy (keV)

FIG. 4. EDS spectra of (a) a light region and (b) a dark region corresponding to the $\alpha$ and $\beta$ in Fig. 3, respectively. 
region is shown to contain $\mathrm{Pd}, \mathrm{In}$, and $\mathrm{Ga}$ as shown in the EDS spectrum given in Fig. 4(b), suggesting that it is the reacted $\mathrm{PdIn}_{y} \mathrm{Ga}_{1-y}$. The presence of $\mathrm{Cu}$ peaks in both Figs. 4(a) and 4(b) was due to the ion milling of the $\mathrm{Cu}$ sample holding grid and needs no further discussion. The results of this interface characterization are consistent with the formation of $\operatorname{In}_{x} \mathrm{Ga}_{1-x} \mathrm{As}$ at the contact interface due to the exchange of In and $\mathrm{Ga}$ atoms between PdIn and GaAs substrate.

\section{CONCLUSION}

In summary, the intermetallic compound PdIn is used as a contact metallization to $n-\mathrm{GaAs}$, as it fulfills the criteria for ohmic contact formation via the exchange mechanism. Average specific contact resistances reached $10^{-6} \Omega \mathrm{cm}^{2}$ range upon annealing at $600{ }^{\circ} \mathrm{C}$ or above. Specific contact resistances as low as $2.5 \times 10^{-6} \Omega \mathrm{cm}^{2}$ were obtained after annealing at $850{ }^{\circ} \mathrm{C}$ for $15 \mathrm{~s}$. The contacts exhibited excellent thermal stability after being subjected to a heat treatment of $400{ }^{\circ} \mathrm{C}$ for $100 \mathrm{~h}$, while their electrical properties degraded after a similar thermal aging at $500{ }^{\circ} \mathrm{C}$ for $100 \mathrm{~h}$. Interfacial characterization by cross-sectional TEM suggests that the formation of $\operatorname{In}_{x} \mathrm{Ga}_{1-x}$ As is due to the exchange of In and $\mathrm{Ga}$ atoms at the contact interface, consistent with the exchange mechanism.

\section{ACKNOWLEDGMENT}

The authors gratefully acknowledge the support of National Science Foundation for this project through Grant No. NSF-DMR-94-24478. They also wish to thank D. B. Ingerly for reviewing this manuscript.

${ }^{1}$ L. H. Allen, L. S. Hung, K. L. Kavanagh, J. R. Phillips, A. J. Yu, and J. W. Meyer, Appl. Phys. Lett. 51, 326 (1987).

${ }^{2}$ G. Stremsdoerfer, J. R. Martin, P. Clechet, and N. Du, J. Electrochem. Soc. 137, 256 (1990).

${ }^{3}$ L. C. Wang, X. Z. Wang, S. S. Lau, T. Sands, W. K. Chan, and T. F. Kuech, Appl. Phys. Lett. 56, 2129 (1990).

${ }^{4}$ K. Prasad, L. Faraone, and A. G. Nassibian, Electron. Lett. 27, 149 (1991).

${ }^{5}$ L. C. Wang, X. Z. Wang, S. N. Hsu, S. S. Lau, P. S. D. Lin, T. Sands, S. A. Schwarz, D. L. Plumton, and T. F. Kuech, J. Appl. Phys. 69, 4364 (1991).

${ }^{6}$ T. Pirling, K. Fricke, M. Schussler, W. Y. Lee, H. Fuess, and H. L. Hartnagel, Mater. Sci. Eng. B 29, 70 (1995).

${ }^{7}$ H. G. Fu and T. S. Huang, Solid-State Electron. 38, 89 (1995).

${ }^{8}$ H. G. Fu and T. S. Huang, Solid-State Electron. 38, 1299 (1995).

${ }^{9}$ T. Sands, E. D. Marshall, and L. C. Wang, J. Mater. Res. 3, 914 (1988).

${ }^{10}$ J.-C. Lin, K. J. Schulz, K.-C. Hsieh, and Y. A. Chang, J. Mater. Res. 3, 148 (1988).

${ }^{11}$ T. Sands, W. K. Chan, C. C. Chang, E. W. Chase, and V. G. Keramidas, Appl. Phys. Lett. 52, 1338 (1988).

${ }^{12}$ C.-H. Jan, Ph.D. thesis, University of Wisconsin-Madison, 1991.

${ }^{13}$ Y. A. Chang, Mater. Res. Soc. Symp. Proc. 260, 43 (1992).

${ }^{14}$ Y. A. Chang, C.-H. Jan, and C.-P. Chen, U.S. Patent No. 5,516,725 (1996).

${ }^{15}$ D. Y. Chen, Y. A. Chang, and D. Swenson, Appl. Phys. Lett. 68, 96 (1996).

${ }^{16}$ D. Y. Chen and Y. A. Chang (unpublished results).

${ }^{17}$ E. Kuphal, Solid-State Electron. 24, 69 (1981). 